\title{
Root Tip Meristematic Cell and Leaf Chloroplast Structure in Three Barley (H. vulgare L.) Genotypes Exposed to Salinity Stress
}

\author{
Y. El-Banna and T. Attia* \\ Department of Biological Sciences, Faculty of Science, Kuwait University, P. O. Box 5969, Safat 13060, Kuwait
}

Accepted December 14, 1998

\begin{abstract}
Summary The effect of salinity on the ultrastructure of the chloroplast in the leaf and meristematic cells in the root tips was investigated in three barley genotypes, California Mariout, a salt-tolerant genotype, and two salt-sensitive genotypes, Teo and ICARDA 17. Salinity induced clear changes in the ultrastructure of the chloroplast. The most notable change was disorientated lamellar system with the grana and intergrana lamellae becoming swollen. The chloroplasts of California Mariout were less affected by salinity than those of ICARDA 17. Meristematic cells in the root tips exhibited various degrees of disruption in internal structure: vesiculated plasmalemma, accumulation of lipid droplets, vacuolation of cytoplasm and swelling to a complete damage of mitochondria were observed in the salinity treated plants.
\end{abstract}

Key words Chloroplast structure, Root tip meristematic cells, Salinity, Barley, Salt tolerance, Hordeum vulgare.

Soil salinity is an important agricultural problem, especially in farm lands dependent on irrigation. The problem is compounded by the relatively low salt tolerance of most crop plants. It has long been known that soil salinity is a major concern in agriculture of arid and semi-arid regions. Approximately one-third of the world's land surface is arid or semi-arid, of which one-half is estimated to be affected by salinity (Serrato Valenti et al. 1991, Ben Rais et al. 1993).

Adaptation of plants to saline environments is a complex process. Through exclusion, excretion or dilution mechanism, the cells have to prevent themselves from large accumulation of ions in their cytoplasm (Hamza 1980, Ben Rais et al. 1993). Then, the specific morphological and biochemical modification which occurs in each species might reflect the individual adaptive capacity of the plants (Ben Rais et al. 1993). The molecular basis of salinity tolerance among various plant species is not understood. Genotypic variation for salinity tolerance has been observed in many plants including barley (Sayed 1985, Ramagopal 1987).

Barley is cultivated in many areas exposed to salinity due to irrigation or saline subsoil and is regarded as moderately salt tolerant among glycophyte species (Hurkman et al. 1989, Robinson et al. 1990, Hurkman 1992). The aim of the present investigation was to study the effects of various concentrations of salt in the nutrient medium on the structures of barley leaf chloroplast and root tip meristematic cells and compare them in barley genotypes differing in their reaction to salinity, either tolerant (California Mariout) or sensitive (Teo followed by ICR 17). Chloroplasts and meristematic root tips were chosen as indicators of degree of salinity effects on such major plant activities as photosynthesis and root growth.

* To whom correspondence should be addressed. e-mail: attia@kuc01.kuniv.edu.kw 
Materials and methods

\section{Plant material}

Seeds of barley, California Mariout, Teo and ICARDA 17, were cultivated in vermiculite supplemented with a complete Hoagland's nutrient solution salinized with 5000, 10000 or $15000 \mathrm{ppm}$ salinity $\left(3 \mathrm{NaCl}: 1 \mathrm{CaCl}_{2}\right)$. Nutrient solution without the salts was used as a control test. All the treatments were grown in the green house under controlled temperature and light conditions.

\section{Chloroplast ultrastructure}

Mesophyll leaf chloroplasts preparations for electron microscopic studies were made using the middle portion of the third leaves of California Mariout and ICA 17 genotypes.

\section{Root tip meristematic cells}

Samples were collected from root tips of California Mariout and Teo genotypes. The collected materials from leaves and root tips were passed through the following basic steps of fixation, dehydration, embedding, sectioning, mounting, viewing and photography.

Double fixation in glutaraldehyde $(2.5 \%)$ and osmium tetroxide $(1 \%)$ was used. The fixative solutions were prepared in $0.01 \mathrm{M}$ phosphate buffer of $\mathrm{pH} 6.5$. Glutaraldehyde was used first for overnight in the refrigerator and replaced with cold buffer for $15 \mathrm{~min}$, then the buffer was replaced with osmium tetroxide for $1 \mathrm{~h}$. Most of the osmium tetroxide was removed and replaced with two changes of buffer. The materials were passed along the dehydration gradient by substituting the buffer with $50,70,80,95$ and $100 \%$ acetone, $10-15 \mathrm{~min}$ in each except $100 \%$ for which two changes of $30 \mathrm{~min}$ were made. The pure acetone was replaced gradually with a mixture of acetone and epoxy resin. The dilute resin was then replaced with pure resin for overnight and was replaced again with fresh resin for $2 \mathrm{hr}$ and the materials were thus ready for embedding.

Thick sections were made first to select the suitable area for ultrathin section $(50-100 \mu \mathrm{m})$ using Reichert ultramicrotome. Sections were collected on copper grids, and double stained with saturated uranyl acetate in $70 \%$ ethanol and Reynold's lead citrate for $15 \mathrm{~min}$ each. Sections were viewed, investigated and photographed, using transmission electron microscopy (JEOL's Jem 1200 EXII).

The results obtained were presented qualitatively using photomicrographs of many electron microscopic fields taken from several investigated samples of both control and treated plants.

Results

\section{Chloroplast ultrastructure}

Control plants Typical chloroplasts from mature barley leaf tissues with well defined chloroplast structures are shown in Figs. 1A, 2A. The chloroplast possessed typical well developed grana and stroma thylakoids, which were generally oriented parallel to the long axis of the plastid. The compact stroma contained few starch grains.

Salinity treated plants In contrast to control plants, leaf tissues exposed to salinity showed a sequence of ultrastructural changes with increasing salinity levels (Figs. 1B, C, D, 2B, C, D). With low level of salinity $(5000 \mathrm{ppm})$, some chloroplasts showed dilation of thylakoids, although the internal membrane network was still intact (Figs. 1B, 2B). With high level of salinity (10000 and $15000 \mathrm{ppm}$ ), the most notable change was disorientated lamellar system with the grana and intergrana lamellae becoming swollen (Figs. 1C, D, 2C, D).

In comparison between the two genotypes, California Mariout and ICA 17, we can say that California Mariout is more tolerant than ICA 17 hence the severe effect of salinity on chloroplast structure starts with low level of salinity $(5000 \mathrm{ppm})$ in case of ICA 17 (Fig. 2B), while it starts 

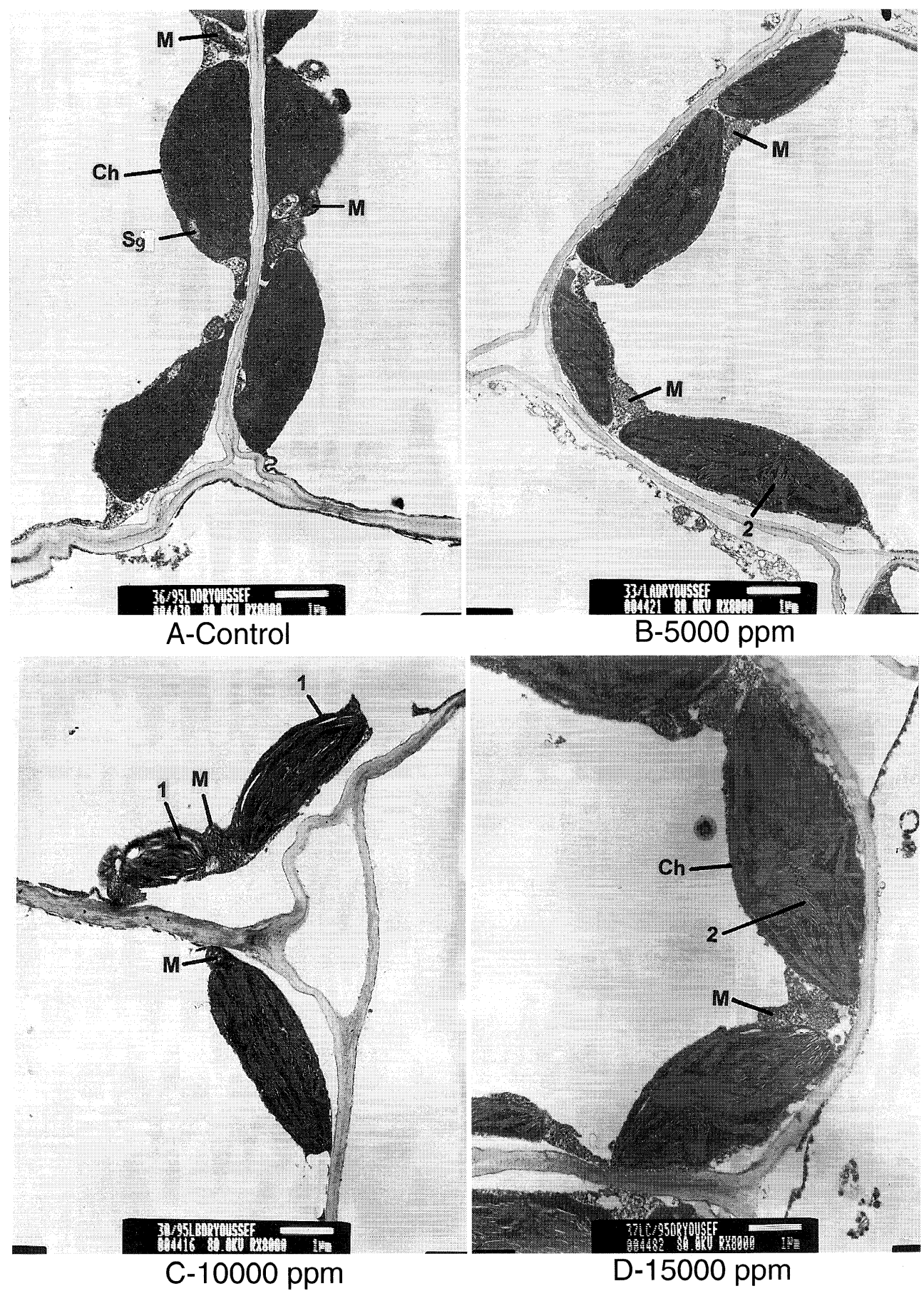

Fig. 1. Transmission electron micrographs of mesophyll cells of barley (California genotype). $M=$ mitochondria, $\mathrm{Ch}=$ chloroplast, $\mathrm{Sg}=$ starch grain, arrow 1 indicates dilated thylakoids and arrow 2 indicates disorganization of internal membranes. 

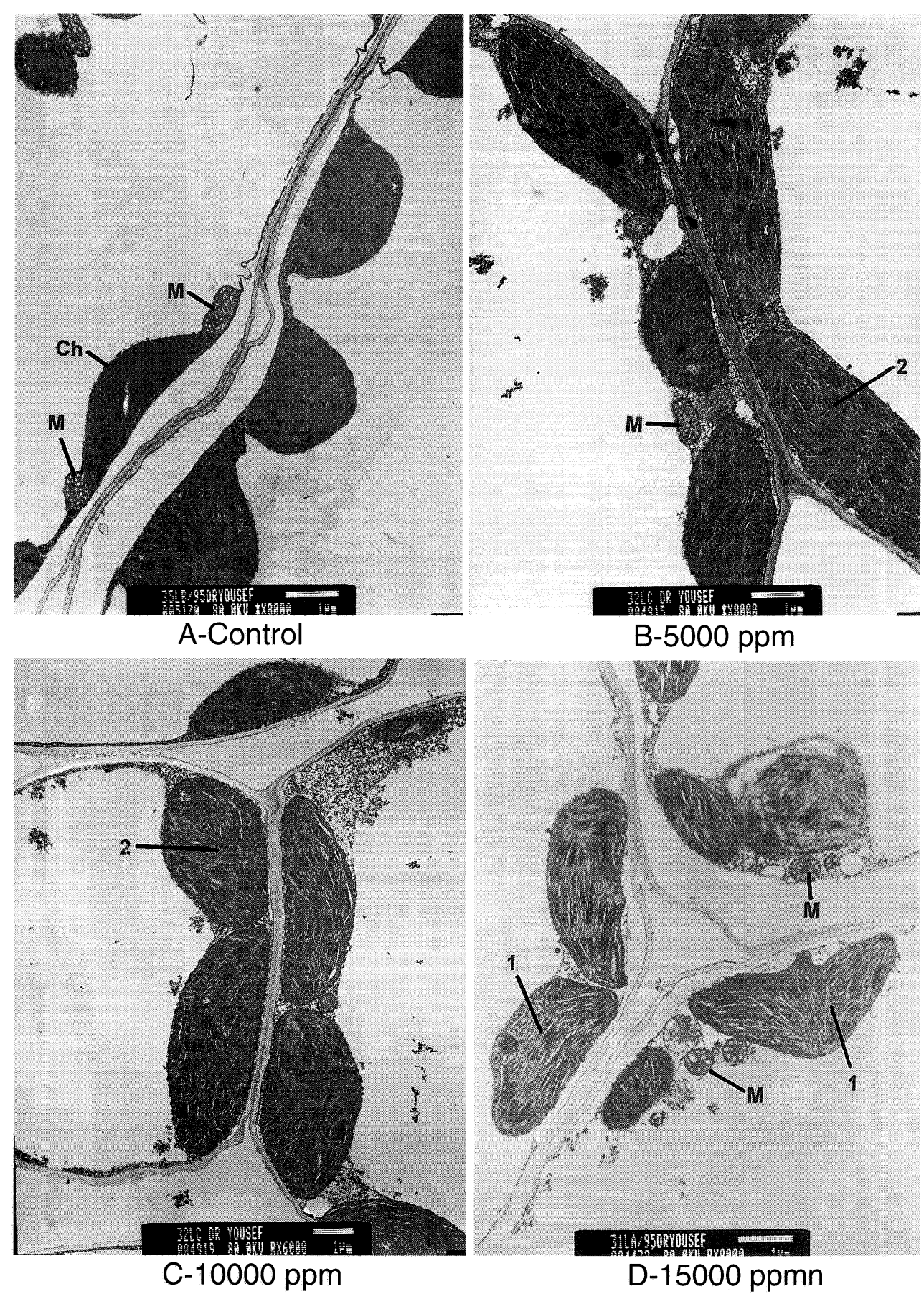

Fig. 2. Transmission electron micrographs of mesophyll cells of barley leaf (Icarda 17). Abbrev. as in Fig. 1. 


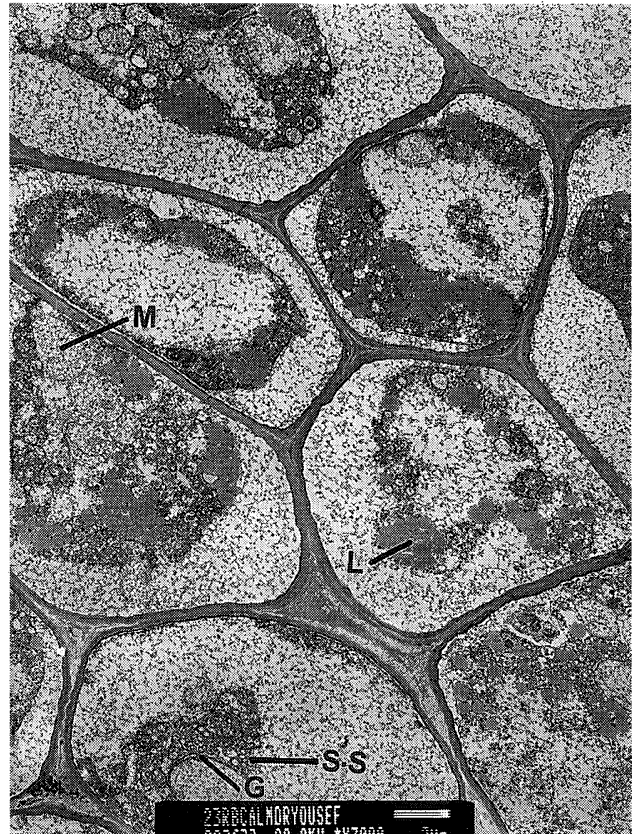

A-Control

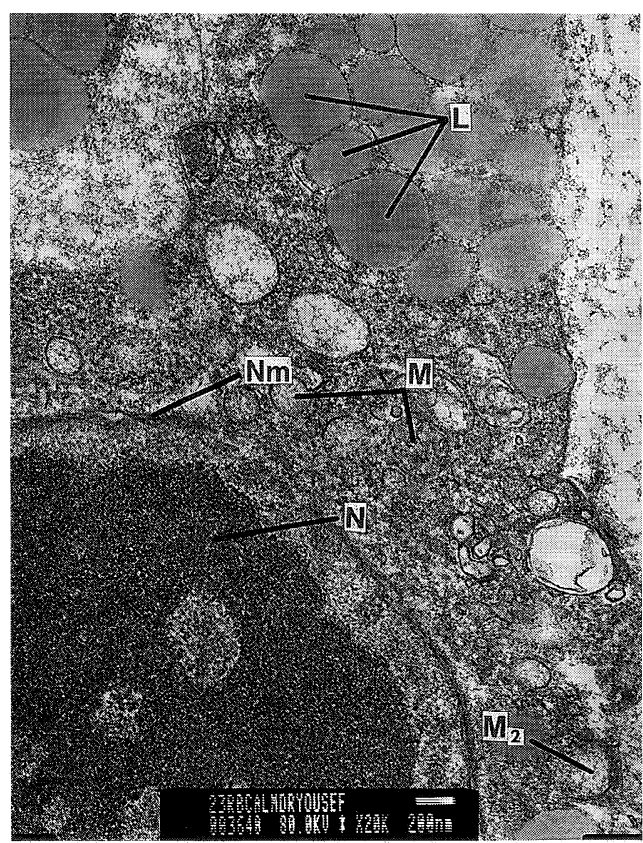

C-10000 ppm

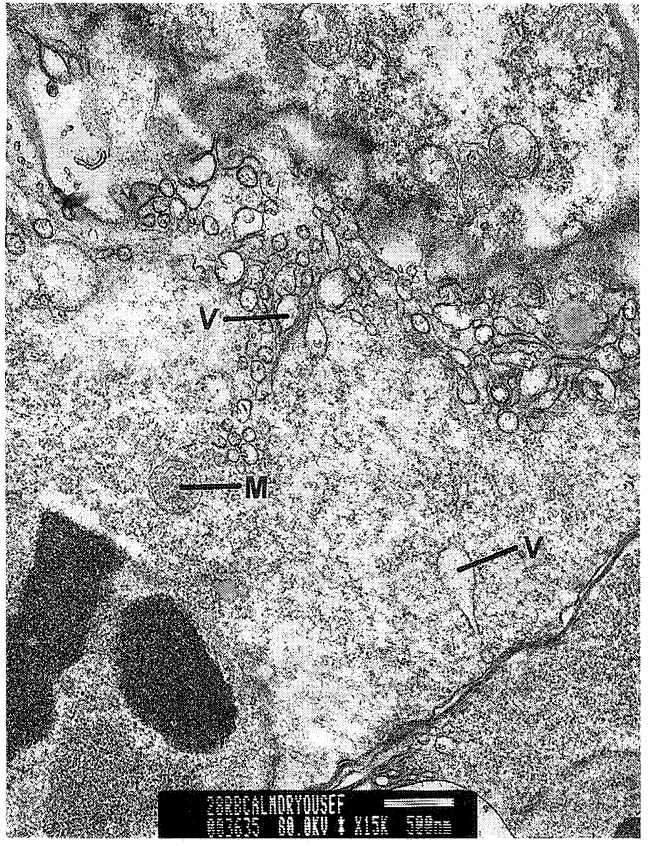

B-5000 pm

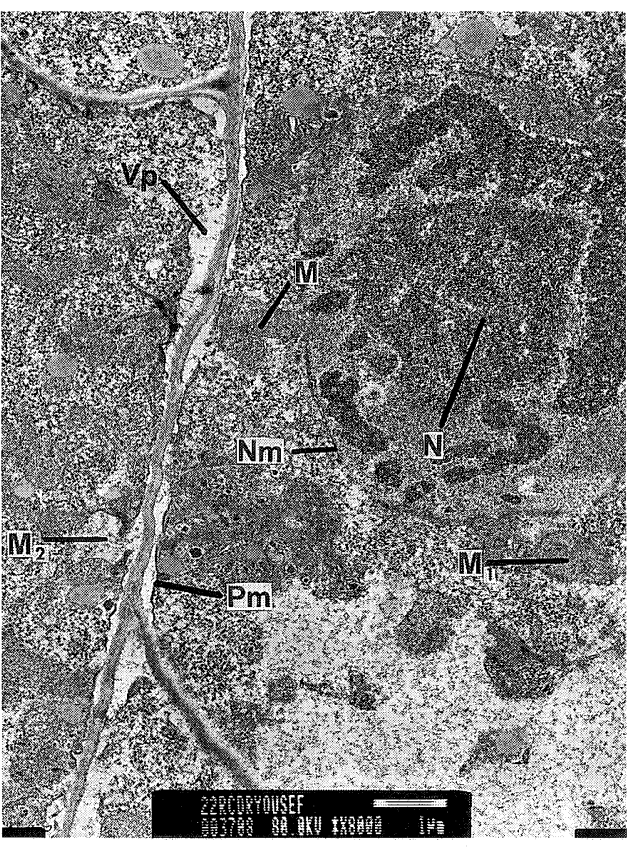

D-15000 ppm

Fig. 3. Transmission electron micrographs of California genotype root tips. $\mathrm{L}=$ lipid droplets, $\mathrm{Nm}=$ nuclear membrane, $\mathrm{SS}=$ small splitting vesicle, $\mathrm{N}=$ nucleus, $\mathrm{M}=$ mitochondria, $\mathrm{M}_{1}=$ deep folding mitochondria, $\mathrm{M}_{2}$ = complete degradation of mitochondria, $\mathrm{V}=$ vacuolation of cytoplasm, $\mathrm{Vp}=$ vesiculated plasma and $\mathrm{Pm}=$ plasmalemma separated from cell wall. 


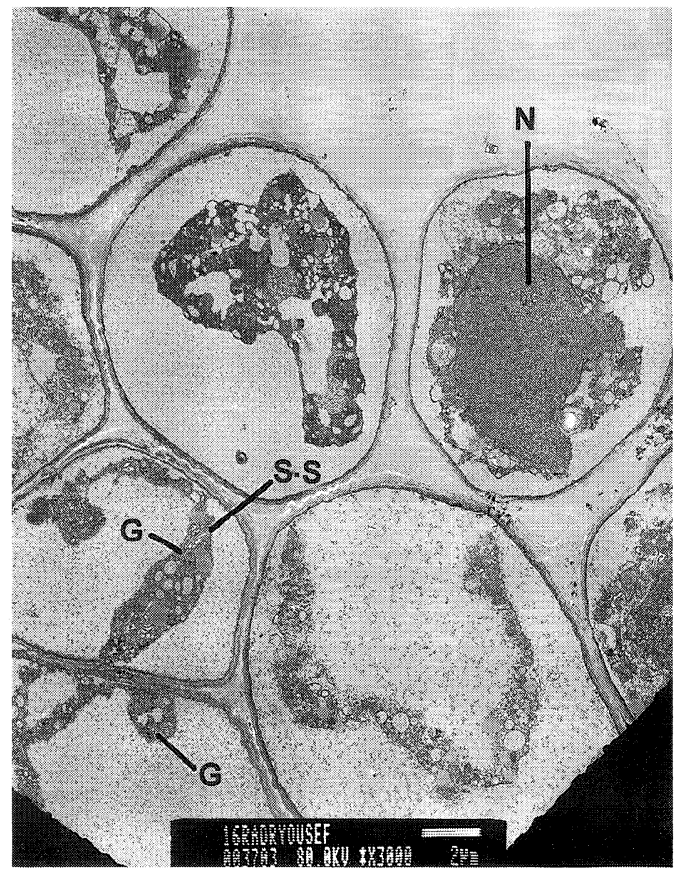

A-Control

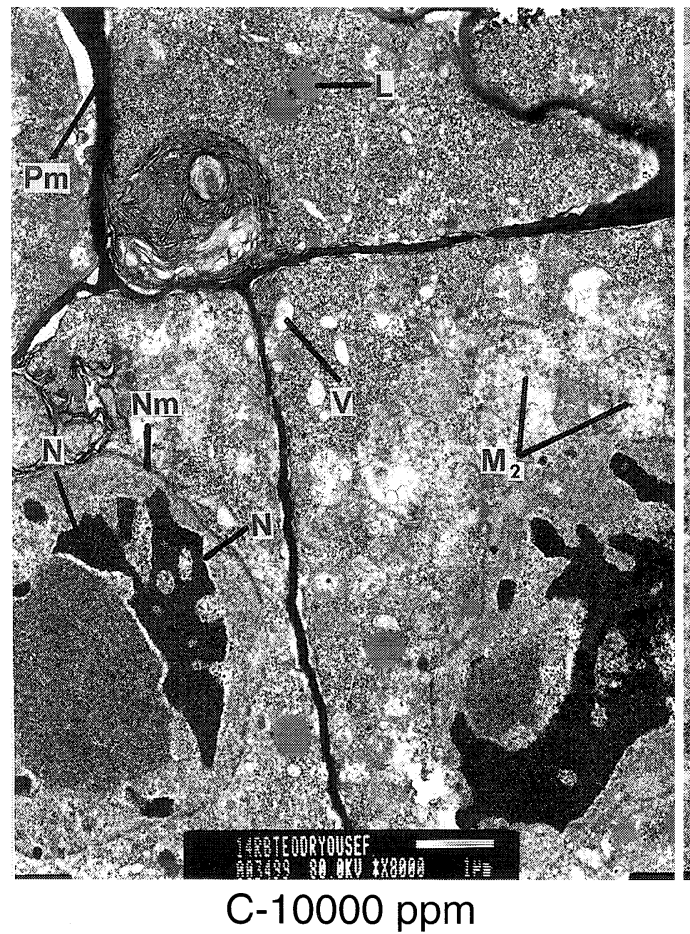

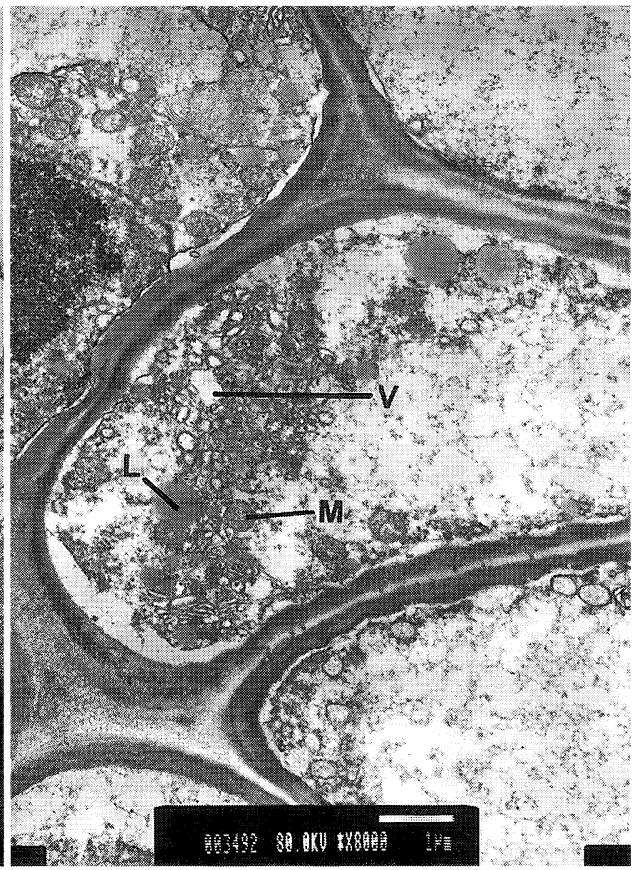

B-5000 ppm

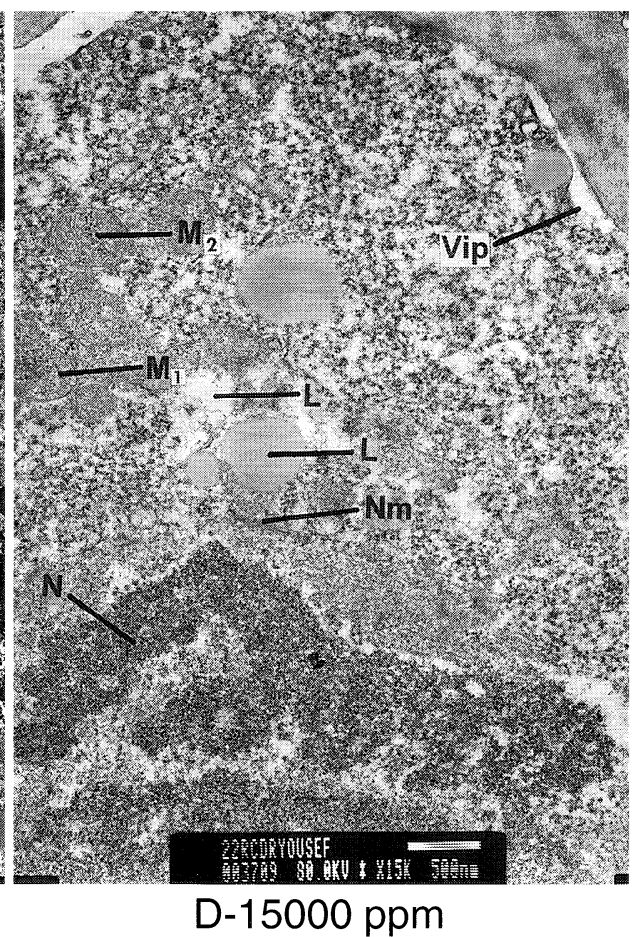

Fig. 4. Transmission electron micrographs of Teo genotype root tips. Abbrev. as Fig. 3. 
with the higher level (10000 ppm) is case of California Mariout (Fig. 1C).

\section{Root tip meristematic cells}

Control plants Meristematic cells of untreated plants (control) appeared normal with dense cytoplasm, big nucleus, mitochondria with clear double membrane and normal distribution of cristae and Golgi apparatus with flat cisternae and small splitting vesicles (Figs. 3A, 4A).

Salinity treated plants Investigation of root tip meristematic cells exhibits various degrees of disruption in internal cell structure. Vesiculated plasmalemmas separated from cell wall (Figs. 3D, 4D), tendency for more accumulation of lipids droplets in cytoplasm (Fig. 3C) compared to control (Fig. 3A) and vacuolation of cytoplasm (Figs. 3B, C, 4C) were observed. Various stages of damage to mitochondrion were observed, from swelling mitochondria with a deep infolding of the inner membrane envelope (Figs. 3D, 4D) to a complete degeneration of mitochondria (Figs. 3D, 4C). Root meristematic cells of California Mariout and Teo showed the same types of ultrastructural changes, however they started to be more observable and pronounced in Teo at lower salt concentrations than in California Mariout.

\section{Discussion}

Salinity stress caused alterations in the structure of chloroplast and root tip meristematic cells of barley plant. Comparable results in chloroplast structure have also been observed by Vadovenko and Tsibkovskaya (1983), El-Banna (1985), Salama et al. (1994) and in root tip meristematic cells by Strogonov (1974), Smith et al. (1982), El-Banna (1985). Although the stress affected the two barley genotypes, there were clear differences in chloroplast structure under the stress conditions between the more tolerant genotype California Mariout and the less tolerant genotype ICA 17. Chloroplasts in California Mariout were less affected by salinity stress than those of ICA 17. Similar observation was made by Ramagopal (1987) with Califronia Mariout.

Under high salinity $(200 \mathrm{mM} \mathrm{NaCl})$, chloroplast thylakoid membranes swelled in wheat cultivars differing in their salt tolerance to slightly different extents (Salama et al. 1994). Mono- or divalent cations lead to stacking of adjacent membranes in grana (Barber 1982). Thus, swelling of thylakoid membranes is probably due to a change in the ionic composition of the stroma liquid, rather than an effect of soidium ions on stacking of membranes.

The observed injurious effect to the root tip meristematic cell organelles could be a direct effect of ions $\left(\mathrm{Na}^{+}, \mathrm{Ca}^{++}\right.$and $\mathrm{Cl}^{-}$) within the cell or the organelles (Poljakoff-Mayber and Gale 1975, Smith et al. 1982). Accumulation of these ions could lead to observed abnormalities in cytoplasm, plasma lemma or mitochondria. Higher degree of salt tolerance is usually associated with less incidence and intensity of such changes in root tip meristematic cells. It could also be a type of response to water stress imposed by the total soluble salts in the growing media (Ristic and Cass 1991).

Understanding how plants survive under salt stress is complicated by a number of factors. Salt stress consists of several components reducing water potential, specific ion stress or toxicity, ion imbalance or nutrient deficiency (Yeo 1983). Information on physiological, biochemical and metabolic processes indicates that the response to salt stress varies with salt concentration, type of salt, length of exposure, presence of other ions, and environmental conditions, including temperature, humidity and available soil moisture. In addition, the stress response is dependent upon stage of plant development, hormonal balance, and diurnal rhythms. Therefore, the effect of excess soluble ions on vital processes of the cell must be studied from the molecular-cytological aspects. The vital process of the cell begins early during cell division and the primary biological information of the cell is expressed morphologically in the form of subcellular structure, such as nucleus, chloroplasts and mitochondria (Strogonov 1974). More studies are needed on these structures and their respons- 
es to salinity. Such studies should contribute toward an understanding of the basic mechanisms by which salinity affects various cellular activities.

\section{Acknowledgements}

We would like to thank Kuwait Foundation for the Advancement of Sciences (KFAS) and the office of Vice President, Research Administration, University of Kuwait for their financial support of our research project Soo55. Thanks are also due to Miss Asmaa Hanif for her excellent technical help.

\section{References}

Barber, J. 1982. Influence of surface charges on thylakoid structure and function. Ann. Rev. Plant Physiol. 33: $261-295$.

Ben Rais, L., Alpha, M., Bahl, J., Guillot-Salomon, T, and Dubacq, J. 1993. Lipid and protein contents of Jojoba leaves in relation to salt adaptation. Plant Physiol. and Biochem. 31: 547-557.

El-Banna, Y. 1985. The effects of salinity on the morphology, anatomy and ultrastructure of field bean and wheat plants and their modification by selected growth-regulating chemicals. Ph. D. thesis, Univ. of London,

Hamza, M. 1980. Reponses des vegetaux à la salinite. Physiology Vegetale 18: 69-81.

Hurkman, W. J. 1992. Effect of salt stress on plant gene expression: A review. Plant and Soil 146: 145-151.

- Fornari, C. S. and Tanaka, C. K. 1989. A comparison of the effect of salt on polypeptides and translatable mRNAs in roots of a salt-tolerant and a salt-sensitive cultivar of barley. Plant Physiol, 90: 1444-1456.

Poljakoff-Mayber, A. and Gale, J. 1975. Plants in Saline Environments. Springer Verlag, New York, 213 pp.

Ramagopal, S. 1987. Salinity stress induced tissue-specific protein in barley seedlings. Plant Physiol. 84: 324-331.

Ristic, Z. and Cass, D. D. 1991. Chloroplast structure after water shortage and high temperature in two lines of Zea mays L. that differ in drought resistance. Bot. Gaz. 152(2): 186-194.

Robinson, N. L., Tanaka, C. K. and Hurkman, W. J. 1990. Time dependent changes in polypeptide and translatable mRNA levels caused by $\mathrm{NaCl}$ in barley roots. Physiol. Plantarum 78: 128-134.

Salama, S., Trivedi, S., Busheva, M., Arafa, A. A., Garab, G. and Erdei, L. 1994. Effect of NaCl salinity on growth, cation accumulation, chloroplast structure and function in wheat cultivars differing in salt tolerance. J. Plant Physiol. 144: $241-247$.

Sayed, H. I. 1985. Diversity of salt-tolerance in a germplasm in pea epicotyls. Plant Physiol. 73: 809-816.

Serrato Valenti, G., Ferro, M., Ferraro, D. and Riveros, F. 1991. Anatomical changes in Prosopis tamarugo phil seedlings growing at different levels of $\mathrm{NaCl}$ salinity. Annals of Bot. 68: 47-53.

Smith, M. M., Hodson, M. J., Opik, H. and Wainwright, S. J. 1982. Salt induced ultrastructural damage to mitochondria in root tips of a salt-sensitive ecotype of Agrostis stolonifera. J. Exptl. Bot. 33: 886-895.

Strogonov, B. P. 1974. Structure and Function of Plant Cells in Saline Habitats. New York, London: Israel Program for Scientific Translation, $284 \mathrm{pp}$.

Vadovenko, G. V. and Tsibkovskaya, N. S. 1983. Dynamics of ultrastructural changes in barley leaf cells organelles under salinization. Fiziologia Rastenii 30: 518-526.

Yeo, A. R. 1983. Salinity resistance: physiologies and prices. Physiol. Plantarum 58: 214-222. 